\title{
Family-Witnessed Resuscitation: Perceptions of Nurses and Doctors Working in an Australian Emergency Department
}

\author{
Rose Chapman, ${ }^{1,2}$ Rochelle Watkins, ${ }^{3}$ Angela Bushby, ${ }^{4}$ and Shane Combs ${ }^{2}$ \\ ${ }^{1}$ School of Nursing and Midwifery, Curtin University, GPO Box U1987, Perth, WA 6845, Australia \\ ${ }^{2}$ Nursing Executive, Joondalup Health Campus, Shenton Avenue, Joondalup, WA 6027, Australia \\ ${ }^{3}$ Telethon Institute for Child Health Research, Centre for Child Health Research, The University of Western Australia, \\ P.O. Box 855, West Perth, WA 6872, Australia \\ ${ }^{4}$ Department of Emergency, Joondalup Health Campus, Shenton Avenue, Joondalup, WA 6027, Australia
}

Correspondence should be addressed to Rose Chapman, r.chapman@curtin.edu.au

Received 2 October 2011; Accepted 2 November 2011

Academic Editors: P. Eisenburger, A. Eisenman, W. Kloeck, and A. Pazin-Filho

Copyright (C 2012 Rose Chapman et al. This is an open access article distributed under the Creative Commons Attribution License, which permits unrestricted use, distribution, and reproduction in any medium, provided the original work is properly cited.

\begin{abstract}
Inconsistencies abound in the literature regarding staff attitudes and perceptions toward family-witnessed resuscitation. Our study builds on previous research by using a validated tool to investigate emergency department staff perceptions of family-witnessed resuscitation. A cross-sectional survey was distributed to 221 emergency department doctors' and nurses'. We found few differences between doctors and nurses perceptions toward family-witnessed resuscitation. Both nurses and doctors who held a specialty certification, who were more highly qualified, who had more experience with family presence during resuscitation, and who had a personal preference for having family members present during their own resuscitation perceived more benefits and fewer risks, as well as more confidence in their ability to manage these events. However, nurses more than doctors want patients to provide advanced directives for family presence. The findings will enable clinicians, educators, and hospital management to provide better support to all stakeholders through these events.
\end{abstract}

\section{Introduction and Background}

The inclusion of family members during resuscitation efforts in the emergency department (ED) is supported by many authors and professional bodies [1-5]. The literature has highlighted that friends and family play a significant role in the well-being of patients in the ED [6]. However, debate continues as to the effectiveness of family-witnessed Resuscitation (FWR) for staff, family, and most importantly the patient [7-11]. Resuscitation can be defined as "to revive from apparent death or unconsciousness" [12, p. 1], and studies from the United Kingdom (UK) and the United States of America (USA) have shown that only between 10 and 32 per cent of these interventions are successful [12-16]. Therefore, it would appear that although some resuscitation efforts are successful, many more fail. Staff experiences of these unsuccessful interventions could be compounded during FWR when a patient's loved one is present [17], and this may be one reason clinicians are reluctant to invite family into the resuscitation.
In addition to the negative impact of failed resuscitation, the literature has highlighted several other factors that act as barriers to inviting family members to be present during the resuscitation process. These include concern about the possible negative emotional effect on family members, family behaviour, lack of a nominated staff member to support family, increased stress for staff, the risk of litigation, an overcrowded resuscitation room, resuscitation being stopped too soon or continued longer than necessary, and staff appearing uncaring $[14,18-20]$. As a result of these beliefs staff may have anxieties related to FWR and view the practice negatively.

Attitudes, beliefs, and knowledge of staff have been shown to be the most significant reasons families are not invited to be present during the resuscitation of their loved one [14, 21]. Families want the option to be present [14], and the literature has shown that those families who have been involved in FWR found it a positive experience for themselves and their relative [22-24]. Understanding staff perceptions of FWR is critical to the successful development 
and implementation of effective policy and guidelines to support FWR in the ED. In addition, this information will provide hospital management, clinicians, and educators with information to design effective education and training to support all stakeholders including family and patients.

There is inconsistency in the findings of research exploring staff perceptions toward FWR [25-28]. For example, research has found that doctors more than nurses considered that the family could interfere with treatment and that staff performance might be inhibited [25]. In contrast, a study by Lam et al. [28] found no differences between the attitudes of doctors and nurses working in a paediatric department toward FWR. These variations in study findings could be related to the use of a range of methodologies and the collection of data in different geographical and clinical settings. For example, studies have been conducted in the USA [7, 24, 29$31]$, the UK [25, 27, 32], China [28], and Turkey [26]. Participants have worked in paediatric [28-30] adult [33], mixed adult and paediatric [32], and unknown [26, 31] settings. Data have been collected from staff working in the ED only $[24,31]$, several EDs [32], ED and other areas [7, 26], ICU [27], a cardiac arrest team [25], and staff attending conferences $[29,30]$. Data were collected using tools that were validated [7, 24, 29, 31] and nonvalidated [25-28, 30, 32].

As a result of these differences, few meaningful comparisons between the perceptions of nursing and medical staff toward FWR can be made. This current study builds on previous research by using a validated instrument to describe and compare the perceptions of nursing and medical staff working in the ED of a nonteaching hospital in Western Australia that caters for both paediatric and adult admissions. Understanding staff perceptions and identifying differences in perceptions of self-confidence, risks, benefits, and personal preferences toward FWR may highlight the reasons practitioners choose to invite family presence into the resuscitation of their loved one. This information will provide administrators, educators, and clinicians with a deeper understanding of factors that influence the decisionmaking processes regarding FWR and highlight areas where policy and educational interventions could strengthen the supportive role for families in ED.

\section{Method}

An anonymous, self-administered questionnaire was mailed to all nursing and medical staff working in the ED $(n=$ 221) to assess their perceptions of FWR. Perceptions of selfconfidence, risks, and benefits were assessed using locally validated versions of Twibell et al.'s [11] instruments, the 20-item family presence risk-benefit scale (R-BS) and the 16-item family presence self-confidence scale (S-CS) [34]. Permission to use the original questionnaire was requested and granted from the original authors. The content, factor structure, and performance of the scales in this sample are described elsewhere [34].

The questionnaire collected basic sociodemographic data including age, gender, ethnicity, role (nurse or doctor), highest educational qualification completed, years of experience, presence of clinical specialty certification, and professional organisation membership. As reported by Twibell et al. [11], participants were also asked to report how many times they had invited family members to be present during resuscitation, whether they would want their family members to be present if they were a patient and being resuscitated, whether they had ever been present during the resuscitation of one of their family members, who is the best person to make the decision about family presence during resuscitation, and whether the decision about family presence should be part of an advanced directive authorized by the patient.

Validated versions of two published scales, the R-BS and the S-CS [11], were used to evaluate staff perceptions of their self-confidence with, and the risks and benefits of, familywitnessed resuscitation [34]. The R-BS requires participants to rate their agreement with 20 items using a five-point Likert scale which ranged from strongly disagree (1) to strongly agree (5), with a higher score indicating a greater level of perceived benefit of family-witnessed resuscitation. The SCS requires participants to rate their agreement with 16 items using a five-point Likert scale, which ranged from not at all confident (1) to very confident (5), with a higher score indicating a greater level of self-confidence in managing family-witnessed resuscitation.

Two open-ended items were included at the end of the questionnaire to provide more in-depth data on participant's perceptions of FWR. The two open-ended items were "the main reason I would invite family members into a resuscitation is" and "the main reason I would not invite a family member into a resuscitation is." Participants were sent a letter containing an information sheet, invitation to participate, and self-administered questionnaire along with preaddressed envelope. Consent was implied on return of the questionnaire. Ethics approval for the study was gained from the human research ethics committees of the university and the hospital.

\section{Data Analysis}

Risk-benefit scale scores were calculated by averaging scale scores across the 20 risk-benefit questions after reverse scoring the negatively worded items (item numbers $2,3,7,11$, and 12), and S-CS scores were calculated by averaging scale scores across the 16 self-confidence questions. No S-CS items required reverse scoring, and scale scores were excluded from the analysis when there was more than 1 missing response.

Due to the small sample of doctors obtained, and the skewed distribution of scale scores, differences between scale scores according to sociodemographic and staff characteristics among doctors and nurses were examined using the Mann-Whitney $U$ test. The significance of all comparisons was also examined using the $t$-test, and no differences in conclusions based on significance level were found. MannWhitney $U$ test results are reported for all comparisons. The chi square test of independence was used to test for associations between categorical variables, with Fisher's exact test results reported where the minimum expected cell count was less than 10. Spearman's rank correlation coefficients were also used to describe correlations between variables. Responses to the open ended questions were read line by 
TABLE 1: Sample sociodemographic characteristics, experience with FWR, and perceptions of FWR by role.

\begin{tabular}{|c|c|c|c|}
\hline Characteristic & $\begin{array}{c}\text { Nurses }(n=77) \\
\%(n)\end{array}$ & $\begin{array}{c}\text { Doctors }(n=25) \\
\%(n)\end{array}$ & $P$ \\
\hline \multicolumn{4}{|l|}{ Age } \\
\hline $18-39$ & $48.1(37)$ & $72.0(18)$ & 0.04 \\
\hline 40 years or more & $51.9(40)$ & $28.0(7)$ & \\
\hline Gender & & & $<0.001^{\wedge}$ \\
\hline Female & $89.3(67)$ & $28.0(7)$ & \\
\hline Male & $10.7(8)$ & $72.0(18)$ & \\
\hline Highest qualification & & & $0.056^{\wedge}$ \\
\hline Bachelor or less & $70.1(47)$ & $48.0(12)$ & \\
\hline Postgraduate qualification & $29.9(20)$ & $52.0(13)$ & \\
\hline Specialty certificate & & & 0.14 \\
\hline Yes & $35.1(26)$ & $54.5(12)$ & \\
\hline No & $64.9(48)$ & $45.5(10)$ & \\
\hline Years in current role & & & 0.61 \\
\hline Up to 5 & $42.1(32)$ & $48.0(12)$ & \\
\hline 6 or more & $57.9(44)$ & $52.0(13)$ & \\
\hline Member of a professional body & & & $0.005^{\wedge}$ \\
\hline Yes & $61.4(43)$ & $91.7(22)$ & \\
\hline No & $38.6(27)$ & $8.3(2)$ & \\
\hline Times invited family presence & & & 0.07 \\
\hline Never & $56.6(43)$ & $36.0(9)$ & \\
\hline Ever & $43.4(33)$ & $64.0(16)$ & \\
\hline Best person to decide & & & $0.22^{\wedge}$ \\
\hline Patient or family & $63.8(44)$ & $47.8(11)$ & \\
\hline Nurse or physician & $36.2(25)$ & $52.2(12)$ & \\
\hline Been present for own family & & & $0.45^{\wedge}$ \\
\hline Yes & $10.5(8)$ & $4.0(1)$ & \\
\hline No & $89.5(68)$ & $96.0(24)$ & \\
\hline Want own family present & & & 0.26 \\
\hline Yes & $56.9(41)$ & $44.0(11)$ & \\
\hline No & $43.1(31)$ & $56.0(14)$ & \\
\hline Part of advanced directive & & & 0.040 \\
\hline Yes & $75.0(54)$ & $50.0(12)$ & \\
\hline No & $25.0(18)$ & $50.0(12)$ & \\
\hline
\end{tabular}

${ }^{\wedge}$ Fisher's exact test $P$-value reported.

line and significant words and phrases identified and coded based on the major thrust or intent of each response [35].

\section{Results}

Completed questionnaires were returned by 114 nurses and doctors, giving a response rate of $51.6 \%$. Missing data on staff role (nurse or doctor) for 12 respondents resulted in only 102 respondents being included in the analysis. Selected staff sociodemographic characteristics, beliefs, and experiences are summarized by role in Table 1. Compared with nurses, doctors were significantly more likely to be male, aged less than 40 years, and a member of a professional organization and to believe that the decision about family presence should not be a part of an advanced directive authorized by the patient.

4.1. Perceptions of Risks and Benefits. Differences in R-BS scores according to staff characteristics and beliefs are presented for both doctors and nurses in Table 2. These results show that among both doctors and nurses, staff who held a specialty certification, who were more highly qualified, who reported a greater level of experience in inviting family members to be present during resuscitation, and who had a personal preference for having their own family members present during their own resuscitation were significantly more likely to perceive more benefits and fewer risks associated with FWR. However, we found only among doctors that 
TABLE 2: Differences in the perceptions of risks and benefits of FWR according to staff characteristics, beliefs, and experiences among doctors and nurses.

\begin{tabular}{|c|c|c|c|c|c|c|}
\hline Characteristic & $\begin{array}{c}\text { Doctors } \\
n\end{array}$ & $\begin{array}{c}\text { Doctors } \\
\text { Mean (sd) }\end{array}$ & $P$ & $\begin{array}{c}\text { Nurses } \\
n\end{array}$ & $\begin{array}{c}\text { Nurses } \\
\text { Mean (sd) }\end{array}$ & $P$ \\
\hline Age & & & 0.24 & & & 0.42 \\
\hline $18-39$ years & 18 & $3.01(.78)$ & & 35 & $3.30(0.68)$ & \\
\hline$>39$ years & 7 & $3.41(.67)$ & & 37 & $3.49(0.66)$ & \\
\hline Gender & & & 0.20 & & & 0.66 \\
\hline Female & 7 & $2.76(0.75)$ & & 64 & $3.40(0.70)$ & \\
\hline Male & 18 & $3.26(0.74)$ & & 6 & $3.53(0.25)$ & \\
\hline Ethnicity & & & 0.98 & & & 0.71 \\
\hline Caucasian & 18 & $3.10(0.69)$ & & 67 & $3.40(0.68)$ & \\
\hline Other & 7 & $3.17(0.98)$ & & 4 & $3.53(0.37)$ & \\
\hline Highest qualification & & & 0.03 & & & 0.01 \\
\hline Bachelor or less & 12 & $2.75(0.67)$ & & 44 & $3.29(0.61)$ & \\
\hline Postgraduate & 13 & $3.47(0.69)$ & & 20 & $3.73(0.78)$ & \\
\hline Years in current role & & & 0.008 & & & 0.88 \\
\hline$<6$ & 12 & $2.67(0.64)$ & & 31 & $3.44(0.63)$ & \\
\hline $6+$ & 13 & $3.54(0.62)$ & & 40 & $3.39(0.70)$ & \\
\hline Level of employment ${ }^{\dagger}$ & & & 0.002 & & & 0.16 \\
\hline Junior & 8 & $2.48(0.38)$ & & 54 & $3.31(0.67)$ & \\
\hline Senior & 17 & $3.43(0.70)$ & & 17 & $3.66(0.62)$ & \\
\hline Specialty certificate & & & 0.001 & & & 0.01 \\
\hline Yes & 12 & $3.75(0.30)$ & & 26 & $3.66(0.58)$ & \\
\hline No & 10 & $2.57(0.62)$ & & 44 & $3.22(0.66)$ & \\
\hline Member of a professional body & & & 0.15 & & & 0.97 \\
\hline Yes & 22 & $3.23(0.75)$ & & 41 & $3.45(0.62)$ & \\
\hline No & 2 & $2.40(0.14)$ & & 26 & $3.40(0.74)$ & \\
\hline Times invited family presence & & & $<0.001$ & & & $<0.001$ \\
\hline Never & 9 & $2.43(0.40)$ & & 39 & $3.09(0.66)$ & \\
\hline Ever & 16 & $3.51(0.63)$ & & 32 & $3.77(0.49)$ & \\
\hline Want own family present & & & $<0.001$ & & & $<0.001$ \\
\hline Yes & 11 & $3.82(0.30)$ & & 40 & $3.75(0.40)$ & \\
\hline No & 14 & $2.57(0.51$ & & 27 & $2.85(0.66)$ & \\
\hline Been present for own family & & & - & & & 0.37 \\
\hline Yes & 1 & $2.35-$ & & 8 & $3.66(0.58)$ & \\
\hline No & 24 & $3.15(0.76)$ & & 63 & $3.37(0.68)$ & \\
\hline Part of advanced directive & & & 0.24 & & & 0.41 \\
\hline Yes & 12 & $3.28(0.66)$ & & 52 & $3.45(0.61)$ & \\
\hline No & 12 & $2.88(0.79)$ & & 16 & $3.18(0.84)$ & \\
\hline Best person to decide & & & 0.29 & & & 0.01 \\
\hline Patient or family & 11 & $3.37(0.80)$ & & 43 & $3.57(0.68)$ & \\
\hline Nurse or physician & 12 & $3.01(0.72)$ & & 22 & $3.13(0.64)$ & \\
\hline
\end{tabular}

* Mann-Whitney $U$ test

sd: standard deviation

Higher risk-benefit scale scores indicate perceptions of more benefits and fewer risks

${ }^{\dagger}$ Level of employment: Junior: level 1 nurses and resident medical staff

Senior: level 2 and 3 nurses, registrars, and consultant medical staff 
more senior staff and staff who reported a greater duration of experience in their role were significantly more likely to perceive more benefits and fewer risks associated with FWR.

The small number of doctors surveyed limited the comparison of differences in perceived benefits and risks of FWR by staff characteristics and beliefs, and in particular the comparison of perceived benefits and risks according to professional membership and previous experience with FWR. Both nurses and doctors who believed that patients or family members were the best ones to decide about family presence during resuscitation perceived more benefits and fewer risks associated with FWR compared with staff who believed that nurses or doctors were the best ones to decide; however, these perceptions of risks and benefits differed significantly only among nurses.

4.2. Perceptions of Self-Confidence. Differences in S-CS scores according to staff characteristics and beliefs are presented for both doctors and nurses in Table 3. These results show that among both doctors and nurses, staff who held a specialty certification, who were more senior, who reported a greater duration of experience in their role, and who reported a greater level of experience in inviting family members to be present during resuscitation were significantly more likely to perceive more self-confidence in their ability to manage FWR. Also, although the findings among doctors were nonsignificant, due to the small sample size, observed trends suggest that both nurses and doctors who were more highly qualified, who believed that patients or family members were the best ones to decide about family presence during resuscitation, and those who had a personal preference for having their own family members present during their own resuscitation perceived more self-confidence in their ability to manage FWR. We found only among nurses that older staff were significantly more likely to perceive greater selfconfidence in their ability to manage FWR.

Nurses who had ever been present during the resuscitation of one of their family members reported significantly greater self-confidence compared with nurses who had not been present during the resuscitation of one of their family members. The small number of doctors who had ever been present during the resuscitation of one of their family members prevented the analysis of differences according to personal experience with FWR.

4.3. Correlations among Perceptions. There was a significant positive correlation between perceptions of more benefits and fewer risks and more self-confidence in the ability to manage family presence during resuscitation among both nurses $(r=0.41, P<0.001)$ and doctors $(r=0.66$, $P<0.001$ ). Perceptions that family presence was a right of patients were strongly positively correlated with perceptions of more benefits and fewer risks among both nurses $(r=$ $0.66, P<0.001)$ and doctors $(r=0.77, P<0.001)$, and perceptions of self-confidence in the ability to manage family presence during resuscitation among both nurses $(r=0.35$, $P=0.002)$ and doctors $(r=0.62, P=0.001)$. Perceptions that family members should be given the option to be present during resuscitation were also strongly positively correlated with perceptions of more benefits and fewer risks among both nurses $(r=0.62, P<0.001)$ and doctors $(r=0.84$, $P<0.001)$.

4.4. Reasons Staff Would and Would not Invite Family Presence during Resuscitation. Participants provided detailed qualitative responses to describe the reasons they would or would not invite FWR. These reasons are summarised by occupation and frequency in Table 4 . The main reasons staff would invite family presence were because they considered that it assisted with the grieving process and that it enabled family to see that all efforts had been made and when it was a family option to be included. Alternatively, staff would not invite family presence if their behaviour was considered to be unacceptable, because of limited space in the resuscitation area, when it was against family wishes, or when there was inadequate support for family members.

\section{Discussion}

Previous studies have been conducted to investigate the opinions of doctors and nurses toward FWR [25-28]. However, due to the differences in the design of these studies, the instruments used and variations in perceptions by clinical and cultural context, the comparison of study findings and identification of implication of policy and practice have been problematic. We compared the opinions of doctors and nurses toward FWR using scales that have been shown to be valid in different geographical location and with different populations [11,34]. Our study was the first to compare perceptions of the risks, benefits, and self-confidence to manage FWR between nursing and medical staff using the $\mathrm{R}-\mathrm{BS}$ and S-CS.

Allowing for the small number of doctors surveyed, we found few differences between the professions regarding their perceptions of FWR. Both doctors and nurses who held a specialty certification, who were highly qualified, who had more experience with family presence during resuscitation, and who had a personal preference for having family members present during their own resuscitation perceived more benefits and fewer risks as well as more confidence in their ability to manage these events.

Holding a specialty certification and level of education have previously been shown to be significantly associated with more positive perceptions of FWR. An American study [11] conducted to explore nurses' perceptions of family presence during resuscitation found that certificated nurses and registered nurses perceived more benefits and fewer risks, as well as more confidence in their ability to manage FWR compared to other nurses who were not certificated or registered. Our findings also provide evidence of these associations with specialty certification and educational level among doctors. The literature has highlighted that health professionals who lack education and experience in FWR tend to hold more negative attitudes toward the practice [36].

Similarly, the reported association between increased experience with FWR and perception of more benefits and 
TABLE 3: Differences in the perceptions of self-confidence in managing FWR according to staff characteristics, beliefs, and experiences among doctors and nurses.

\begin{tabular}{|c|c|c|c|c|c|c|}
\hline Characteristic & $\begin{array}{c}\text { Doctors } \\
n\end{array}$ & $\begin{array}{c}\text { Doctors } \\
\text { Mean (sd) }\end{array}$ & $P$ & $\begin{array}{c}\text { Nurses } \\
n\end{array}$ & $\begin{array}{c}\text { Nurses } \\
\text { Mean (sd) }\end{array}$ & $P$ \\
\hline Age & & & 0.30 & & & 0.003 \\
\hline $18-39$ years & 18 & $3.88(0.65)$ & & 35 & $3.47(0.89)$ & \\
\hline$>39$ years & 7 & $4.21(0.51)$ & & 40 & $4.10(0.77)$ & \\
\hline Gender & & & 0.79 & & & 0.86 \\
\hline Female & 7 & $4.00(0.65)$ & & 67 & $3.83(0.91)$ & \\
\hline Male & 18 & $3.95(0.63)$ & & 6 & $3.77(0.53)$ & \\
\hline Ethnicity & & & 0.53 & & & 0.22 \\
\hline Caucasian & 18 & $4.05(0.56)$ & & 69 & $3.84(0.87)$ & \\
\hline Other & 7 & $3.75(0.75)$ & & 5 & $3.30(1.09)$ & \\
\hline Highest qualification & & & 0.09 & & & 0.02 \\
\hline Bachelor or less & 12 & $3.72(0.69)$ & & 46 & $3.68(0.70)$ & \\
\hline Postgraduate & 13 & $4.19(0.46)$ & & 20 & $4.26(1.06)$ & \\
\hline Years in current role & & & 0.02 & & & 0.02 \\
\hline$<6$ & 12 & $3.67(0.71)$ & & 32 & $3.53(0.97)$ & \\
\hline $6+$ & 13 & $4.24(0.37)$ & & 42 & $4.05(0.72)$ & \\
\hline Level of employment $\dagger$ & & & 0.04 & & & $<0.001$ \\
\hline Junior & 8 & $3.59(0.66)$ & & 57 & $3.54(0.83)$ & \\
\hline Senior & 17 & $4.15(0.53)$ & & 17 & $4.64(0.37)$ & \\
\hline Specialty certificate & & & 0.025 & & & $<0.001$ \\
\hline Yes & 12 & $4.23(0.44)$ & & 26 & $4.41(0.58)$ & \\
\hline No & 10 & $3.61(0.66)$ & & 44 & $3.47(0.82)$ & \\
\hline $\begin{array}{l}\text { Member of professional } \\
\text { organisation }\end{array}$ & & & 0.46 & & & 0.24 \\
\hline Yes & 22 & $4.00(0.60)$ & & 42 & $3.97(0.89)$ & \\
\hline No & 2 & $3.47(1.10)$ & & 27 & $3.78(0.77)$ & \\
\hline Times of invited family presence & & & 0.01 & & & $<0.001$ \\
\hline Never & 9 & $3.53(0.53)$ & & 42 & $3.37(0.84)$ & \\
\hline Ever & 16 & $4.21(0.54)$ & & 32 & $4.37(0.57)$ & \\
\hline Want own family present & & & 0.13 & & & 0.03 \\
\hline Yes & 11 & $4.22(0.45)$ & & 40 & $3.99(0.81)$ & \\
\hline No & 14 & $3.77(0.68)$ & & 30 & $3.51(0.94)$ & \\
\hline Been present for own family & & & - & & & 0.01 \\
\hline Yes & 1 & $3.44(-)$ & & 8 & $4.50(0.53)$ & \\
\hline No & 24 & $3.99(0.62)$ & & 66 & $3.72(0.89)$ & \\
\hline Part of advanced directive & & & 0.29 & & & 0.44 \\
\hline Yes & 12 & $4.05(0.56)$ & & 53 & $3.86(0.88)$ & \\
\hline No & 12 & $3.83(0.68)$ & & 17 & $3.63(0.90)$ & \\
\hline Best person to decide & & & 0.06 & & & 0.03 \\
\hline Patient or family & 11 & $4.18(0.62)$ & & 44 & $3.99(0.89)$ & \\
\hline Nurse or physician & 12 & $3.81(0.45)$ & & 25 & $3.55(0.83)$ & \\
\hline
\end{tabular}

* Mann-Whitney $U$ test

sd: standard deviation

Higher self-confidence scale scores indicate greater perceptions of self-confidence

${ }^{\dagger}$ Level of employment: Junior: level 1 nurses and resident medical staff

Senior: level 2 and 3 nurses, registrars, and consultant medical staff. 
TABLE 4: Summary of reasons staff would or would not invite family presence by occupation and frequency of response.

\begin{tabular}{|c|c|c|c|c|c|}
\hline Reasons for & $\begin{array}{l}\text { Doctors } \\
(n)\end{array}$ & $\begin{array}{c}\text { Nurses } \\
(n)\end{array}$ & Reasons why not & $\begin{array}{l}\text { Doctors } \\
(n)\end{array}$ & $\begin{array}{c}\text { Nurses } \\
(n)\end{array}$ \\
\hline Assist with grieving process & 9 & 30 & $\begin{array}{l}\text { Unacceptable behavior } \\
\text { from family }\end{array}$ & 8 & 29 \\
\hline See all efforts have been made & 6 & 30 & Against family wishes & 5 & 8 \\
\hline Family option & 5 & 23 & Inadequate support & 4 & 9 \\
\hline When patient is a child & 1 & 10 & Against patient wishes & 1 & 8 \\
\hline Patient choice & 3 & 5 & $\begin{array}{c}\text { Disruption to resuscitation } \\
\text { process }\end{array}$ & 4 & 3 \\
\hline $\begin{array}{l}\text { Help make the decision (to stop } \\
\text { resuscitation) }\end{array}$ & 0 & 3 & No benefit & 3 & 2 \\
\hline Provide medical history & 0 & 3 & Team being uncomfortable & 2 & 3 \\
\hline \multirow[t]{6}{*}{ Acceptable behaviour (family) } & 1 & 2 & Limited space & 2 & 2 \\
\hline & & & Past negative experience & 1 & 3 \\
\hline & & & When relative is a child & 2 & 1 \\
\hline & & & Aged person & 1 & 2 \\
\hline & & & $\begin{array}{l}\text { Feel pressure to continue } \\
\text { resuscitation }\end{array}$ & 1 & 2 \\
\hline & & & $\begin{array}{c}\text { Performance being } \\
\text { scrutinized }\end{array}$ & 0 & 2 \\
\hline
\end{tabular}

fewer risks and more confidence in their ability to manage these events among nurses [11] was also found among the nurses and doctors in our study. Our findings of the association between perceptions of FWR and personal preference for having family members present during their own resuscitation among both doctors and nurses demonstrate the relevance of personal preferences to clinical decision making of staff related to FWR. These findings may also reflect the current lack of formal education, policy, and strategies to guide staff practices related to FWR in the study hospital $[18,34]$.

We found three main areas of difference in perceptions of FWR among doctors and nurses in our study. Nurses were more likely than doctors to want patients to provide an advanced directive before inviting FWR. An advance directive can be defined as "any expression of a person's thoughts, wishes, or preferences for his or her end-of-life care". Advance directives can be based on conversations, written directives, living wills, or durable powers of attorney for health care" [37]. It may be that the nurses, more than the doctors, in our study lacked confidence and authority to decide to invite family presence into the resuscitation. As a consequence they may have considered that an advanced directive would relieve them of this responsibility. Our finding may also be related to the perception among nurses in this study that decisions about FWR were best made by patients and family members. This could demonstrate the ED nurses's commitment to patient- or family-centered care where the responsibility of deciding to be present during a loved one's resuscitation is moved from the nurse to the patient and family $[19,34]$. Further research is required to provide an in-depth exploration of the reasons why nurses might consider advanced directives to be more desirable than doctors.
More senior and more experienced clinicians, both doctors and nurses, reported greater self-confidence to manage FWR. However, only older nurses perceived increased selfconfidence to manage FWR when compared with their younger colleagues. More senior staff were more confident in their ability to manage the event and communicate with family throughout the resuscitation. This finding differs from Twibell et al. [11] who did not find a relationship between experience or age and perceptions toward FWR among nurses. However, consistent with Twibell et al. [11], we found the perceptions of risks and benefits of FWR only differed significantly by seniority and experience among doctors. These differences found between the professions may be associated with the allocation of roles and responsibilities between doctors and nurses during FWR and the different ways these are enacted between more junior and more senior staff.

The literature has shown that medical staff, especially if they are junior, hold negative attitudes toward FWR compared to other health professionals, and this finding may be related to their inexperience and lack of confidence $[7,8,24,25,30]$. However, in an American study conducted by Duran et al. [7] to explore health care providers, families and patients' attitudes and beliefs about FWR the authors found that the more junior doctors in their study were more positive toward FWR than senior doctors. The authors contend that these differences could be due to training hospitals now involving families in their loved one's care. Offering health care professionals education on issues related to FWR has been shown to promote a more positive attitude towards FWR [8]. However, there appears to be a lack of consensus in the literature as to the impact seniority and experience has on perceptions of FWR, and further empirical research is needed to investigate these effects. 
Unlike Twibell and colleagues [11], we did not find that belonging to a professional organization was associated with significantly different perceptions regarding the risks and benefits of FWR. This finding may be because we only surveyed staff working in the ED where resuscitations frequently occur [38]. In addition, more than $60 \%$ of nurses and $90 \%$ of doctors reported belonging to a professional organization such as the College of Emergency Nursing Australia (CENA) or Australian College of Emergency Medicine (ACEM). Both bodies advocate for family presence during resuscitation, especially for children [39], and, as a result, staff may be more aware of the benefits of FWR.

The literature has highlighted that in the main nurses more than doctors support the concept of FWR [7, 24, 30, 40]. This may be because there are few studies which focus on doctors' perceptions of FWR as compared to those of nurses. In addition, much of the research has been conducted in different locations or settings and on occasion using tools that have not been validated. In order to promote meaningful comparisons of perceptions of FWR between studies and a more comprehensive understanding of FWR, future research should use valid, standardized instruments.

The qualitative findings in this current study were consistent with previous research $[10,14,18,26,32,41,42]$ and demonstrated that participants considered that family presence assisted with the grieving process, provided family members with the opportunity to see all the efforts that had been made to save their relation, enabled family members to provide a medical history to staff, and provided closure if the FWR was not successful.

On the other hand, similar to our study, other authors have also identified reasons why staff are reluctant to invite family presence. These reasons include that they are concerned that the family will behave inappropriately, that the family would not want to witness the resuscitation, that there is lack of space in the resuscitation area, and that there was no one available or allocated as a support person for the family [31]. Health professionals continue to hold concerns that family will disrupt the resuscitation effort and cause stress to the team. However, these concerns have been shown to be unwarranted $[23,31,43]$.

Staff continue to hold inconsistent views as to the benefits and or risks of FWR. Similar to our study previous research has been retrospective in design and aimed to evaluate staff opinion on the subject $[28,29,40]$. Few have included the perceptions of family and relatives $[7,25,27,31]$. In order to gain a holistic view of the benefits and risks of inviting family presence into the resuscitation event from the perspective of all stakeholders, it is essential that future studies include all staff associated with the resuscitation, family members, and patients where possible. To ensure that health care professionals are providing evidence-based care, it is important to examine the impact of FWR over time on those patients who survive and the family members of patients who have and have not survived. The findings from these studies will enable clinicians, educators, and hospital administrators to ensure that they are providing practices that are evidence based and beneficial to all stakeholders.

\section{Limitations}

Major limitations of this study include the use of a convenience sample which limits the generalizability of our findings and the use of a cross-sectional design which limits inferences about causality. Although all ED staff at the hospital were invited to participate in this study, the small sample of doctors limited our ability to identify significant differences in perceptions between doctors and nurses. Studies of larger departments or the recruitment of doctors across multiple departments is required to provide more information on differences in these areas. Longitudinal studies and intervention studies that include patient and family member perspectives are required to understand the determinants of clinical decision making associated with FWR and evaluate policy, education, and support strategies to improve the implementation of FWR in the ED.

\section{Conclusion}

The study was the first to explore the perceptions of Australian ED nurses' and doctors' self-confidence in managing and the risks and benefits of FWR using a validated instrument. These perceptions are significant, and an understanding of the factors associated with positive perceptions of FWR and the existence of differences in perceptions between doctors and nurses is essential to enable clinicians, educators and hospital administrators to develop policy, procedures and education sessions in order to better support families in crisis within the ED setting. Our findings suggest that policy is required to provide staff with improved guidance on the use of FWR. In addition, educational intervention and support are required to improve staff knowledge and to enable the development of practical skills and experience in FWR. An understanding of factors that influence perceptions toward FWR is critical to the design of effective interventions strategies. Our results indicate that few differences exist in the perceptions of nurses and doctors, and as such, few profession-specific influences need to be considered in the design of interventions to support FWR in the ED.

\section{References}

[1] S. E. Krug, T. Bojko, J. A. Fein et al., "Joint policy statementguidelines for care of children in the emergency department," Pediatrics, vol. 124, no. 4, pp. 1233-1243, 2009.

[2] J. E. Davidson, K. Powers, K. M. Hedayat et al., "Clinical practice guidelines for support of the family in the patientcentered intensive care unit: American College of Critical Care Medicine Task Force 2004-2005," Critical Care Medicine, vol. 35, no. 2, pp. 605-622, 2007.

[3] Emergency Nurses Association, "Emergency Nurses Association position statement. Family presence at the bedside during invasive procedures and cardiopulmonary resuscitation," 2011, http://www.ena.org/SiteCollectionDocuments/ Position\%20Statements/FamilyPresence.pdf.

[4] P. Fulbrook, J. Latour, J. Albarran et al., "The presence of family members during cardiopulmonary resuscitation: European Federation of Critical Care Nursing Associations, European Society of Paediatric and Neonatal Intensive Care and 
European Society of Cardiology Council on Cardiovascular Nursing and Allied Professions joint position statement," Connect: The World of Critical Care Nursing, vol. 15, pp. 8688, 2007.

[5] P. Moons and T. M. Norekvål, "European nursing organizations stand up for family presence during cardiopulmonary resuscitation: a joint position statement," Progress in Cardiovascular Nursing, vol. 23, no. 3, pp. 136-139, 2008.

[6] J. Gordon, L. A. Sheppard, and S. Anaf, "The patient experience in the emergency department: a systematic synthesis of qualitative research," International Emergency Nursing, vol. 18, no. 2, pp. 80-88, 2010.

[7] C. R. Duran, K. S. Oman, J. J. Abel, V. M. Koziel, and D. Szymanski, "Attitudes toward and beliefs about family presence: a survey of healthcare providers, patients' families, and patients," American Journal of Critical Care, vol. 16, no. 3, pp. 270-280, 2007.

[8] P. Mian, S. Warchal, S. Whitney, J. Fitzmaurice, and D. Tancredi, "Impact of a multifaceted intervention on nurses' and physicians' attitudes and behaviors toward family presence during resuscitation," Critical Care Nurse, vol. 27, no. 1, pp. 52-61, 2007.

[9] K. Holzhauser and J. Finucane, "Staff attitudes to family presence during resuscitation-part A: an interventional study," Australasian Emergency Nursing Journal, vol. 10, no. 3, pp. 124-133, 2007.

[10] K. Holzhauser and J. Finucane, "Part B: a survey of staff attitudes immediately post-resuscitation to Family Presence during resuscitation," Australasian Emergency Nursing Journal, vol. 11, no. 3, pp. 114-122, 2008.

[11] R. S. Twibell, D. Siela, C. Riwitis et al., "Nurses' perceptions of their self-confidence and the benefits and risks of family presence during resuscitation," American Journal of Critical Care, vol. 17, no. 2, pp. 101-111, 2008.

[12] D. Arawwawala and S. Brett, "Changes to the European Resuscitation Council cardiac arrest management guidelines-a commentary," British Journal of Cardiology, vol. 13, no. 6, pp. 425-429, 2006.

[13] A. Kalbag, Z. Kotyra, M. Richards, K. Spearpoint, and S. J. Brett, "Long-term survival and residual hazard after inhospital cardiac arrest," Resuscitation, vol. 68, no. 1, pp. 79-83, 2006.

[14] E. Madden and C. Condon, "Emergency nurses' current practices and understanding of family presence during CPR," Journal of Emergency Nursing, vol. 33, no. 5, pp. 433-440, 2007.

[15] S. C. Schultz, D. C. Cullinane, M. D. Pasquale, C. Magnant, and S. R. T. Evans, "Predicting in-hospital mortality during cardiopulmonary resuscitation," Resuscitation, vol. 33, no. 1, pp. 13-17, 1996.

[16] H. Tunstall-Pedoe, L. Bailey, D. A. Chamberlain, A. K. Marsden, M. E. Ward, and D. A. Zideman, "Survey of 3765 cardiopulmonary resuscitations in British hospitals (the BRESUS study): methods and overall results," British Medical Journal, vol. 304, no. 6838, pp. 1347-1351, 1992.

[17] N. Jowett and D. Thompson, Comprehensive Coronary Care, Saunders, Edinburgh, UK, 4th edition, 2007.

[18] R. Basol, K. Ohman, J. Simones, and K. Skillings, "Using research to determine support for a policy on family presence during resuscitation," Dimensions of Critical Care Nursing, vol. 28, no. 5, pp. 237-247, 2009.

[19] R. Dougal, J. Anderson, K. Reavy, and C. Shirazi, "Family presence during resuscitation and/or invasive procedures in the Emergency Department: one size does fit all," Journal of Emergency Nursing, vol. 37, pp. 152-157, 2011.
[20] Ü. Güneş and A. Zaybak, "A study of Turkish critical care nurses' perspectives regarding family-witnessed resuscitation," Journal of Clinical Nursing, vol. 18, no. 20, pp. 2907-2915, 2009.

[21] C. Ardley, "Should relatives be denied access to the resuscitation room?" Intensive and Critical Care Nursing, vol. 19, no. 1, pp. 1-10, 2003.

[22] M. Benjamin, J. Holger, and M. Carr, "Personal preferences regarding family member presence during resuscitation," Academic Emergency Medicine, vol. 11, no. 7, pp. 750-753, 2004.

[23] C. Hanson and D. Strawser, "Family presence during cardiopulmonary resuscitation: foote Hospital emergency department's nine-year perspective," Journal of Emergency Nursing, vol. 18, no. 2, pp. 104-106, 1992.

[24] J. A. Mangurten, S. H. Scott, C. E. Guzzetta et al., "Family presence: making room," American Journal of Nursing, vol. 105, no. 5, pp. 40-49, 2005.

[25] A. Blundell, A. Rich, A. Watson, and L. Dale, "Attitudes of doctors and nurses to relatives witnessing cardiopulmonary resuscitation," The Journal of the Royal College of Physicians of Edinburgh, vol. 34, pp. 134-136, 2004.

[26] F. Demir, "Presence of patients' families during cardiopulmonary resuscitation: physicians' and nurses' opinions," Journal of Advanced Nursing, vol. 63, no. 4, pp. 409-416, 2008.

[27] A. S. Grice, P. Picton, and C. D. S. Deakin, "Study examining attitudes of staff, patients and relatives to witnessed resuscitation in adult intensive care units," British Journal of Anaesthesia, vol. 91, no. 6, pp. 820-824, 2003.

[28] D. S. Y. Lam, S. N. Wong, H. Hui, W. Lee, and K. T. So, "Attitudes of doctors and nurses to family presence during paediatric cardiopulmonary resuscitation," Hong Kong Journal of Paediatrics, vol. 12, no. 4, pp. 253-259, 2007.

[29] B. L. Jones, J. Parker-Raley, T. Maxson, and C. Brown, "Understanding health care professionals' views of family presence during pediatric resuscitation," American Journal of Critical Care, vol. 20, no. 3, pp. 199-208, 2011.

[30] B. M. McClenathan, K. G. Torrington, and C. F. T. Uyehara, "Family member presence during cardiopulmonary resuscitation: a survey of US and international critical care professionals," Chest, vol. 122, no. 6, pp. 2204-2211, 2002.

[31] T. A. Meyers, B. J. Eichhorn, C. E. Guzzetta et al., "Family presence during invasive procedures and resuscitation: the experience of family members, nurses, and physicians," American Journal of Nursing, vol. 100, no. 2, pp. 32-42, 2000.

[32] M. G. Booth, L. Woolrich, and J. Kinsella, "Family witnessed resuscitation in UK emergency departments: a survey of practice," European Journal of Anaesthesiology, vol. 21, no. 9, pp. 725-728, 2004.

[33] K. S. Oman and C. R. Duran, "Health care providers' evaluations of family presence during resuscitation," Journal of Emergency Nursing, vol. 36, no. 6, pp. 524-533, 2010.

[34] R. Chapman, R. Watkins, A. Bushby, and S. Combs, "Assessing Health Professionals' perceptions of family presence during resuscitation: a replication study," International Emergency Nursing. In press.

[35] H. Speziale-Streubert and D. Carpenter, Qualitative Research in Nursing Advancing the Humanistic Imperative, Lippincott, Philadelphia, Pa, USA, 2003.

[36] A. Badir and D. Sepit, "Family presence during CPR: a study of the experiences and opinions of Turkish critical care nurses," International Journal of Nursing Studies, vol. 44, no. 1, pp. 8392, 2007. 
[37] "American Heart Association Guidelines for Cardiopulmonary Resuscitation and Emergency Cardiovascular Carepart 2: ethical issues," Circulation, vol. 112, pp. 6-11, 2005.

[38] O. Fulde, "Deaths and dara," Emergency Medicine, vol. 7, pp. 134-135, 1995.

[39] M. K. Hill, M. Pawsey, A. Cutler, J. L. Holt, and S. R. Goldfeld, "Consensus standards for the care of children and adolescents in Australian health services," Medical Journal of Australia, vol. 194, no. 2, pp. 78-82, 2011.

[40] S. D. Helmer, R. S. Smith, J. M. Dort, W. M. Shapiro, and B. S. Katan, "Family presence during trauma resuscitation: a survey of AAST and ENA members," Journal of Trauma, vol. 48, no. 6, pp. 1015-1024, 2000.

[41] E. Lowry, “"It's just what we do": a qualitative study of emergency nurses working with well-established family presence protocol," Journal of Emergency Nursing. In press.

[42] S. E. McClement, W. M. Fallis, and A. Pereira, "Family presence during resuscitation: Canadian critical care nurses' perspectives," Journal of Nursing Scholarship, vol. 41, no. 3, pp. 233-240, 2009.

[43] W. Walker, "Accident and emergency staff opinion on the effects of family presence during adult resuscitation: critical literature review," Journal of Advanced Nursing, vol. 61, no. 4, pp. 348-362, 2008. 


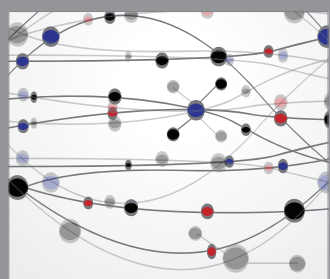

The Scientific World Journal
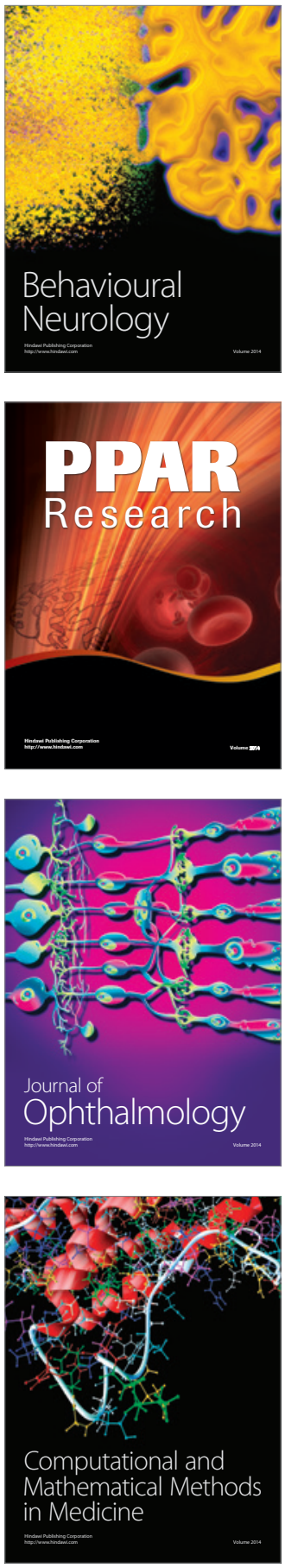

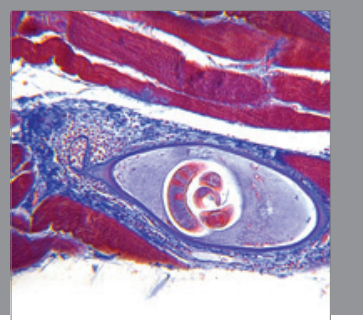

Gastroenterology

Research and Practice
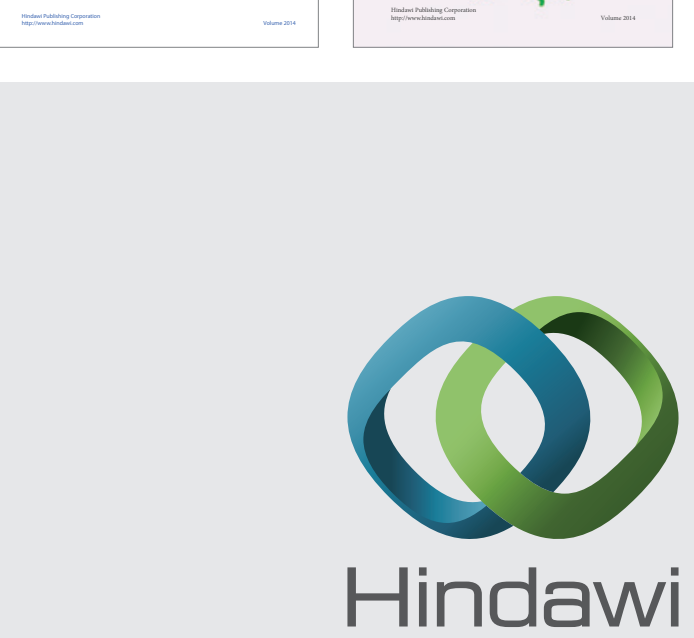

Submit your manuscripts at

http://www.hindawi.com
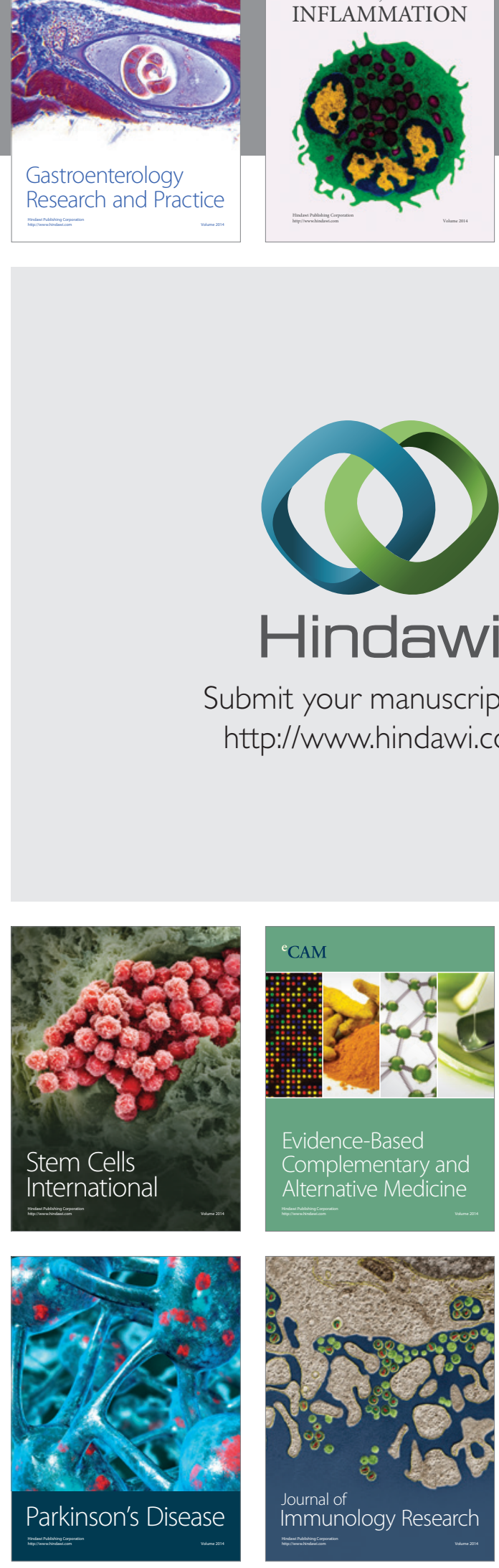

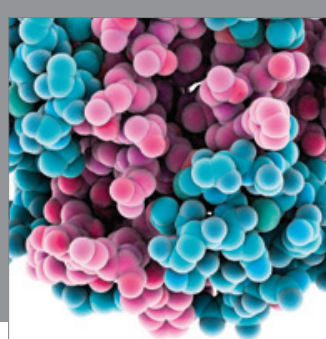

Diabetes Research
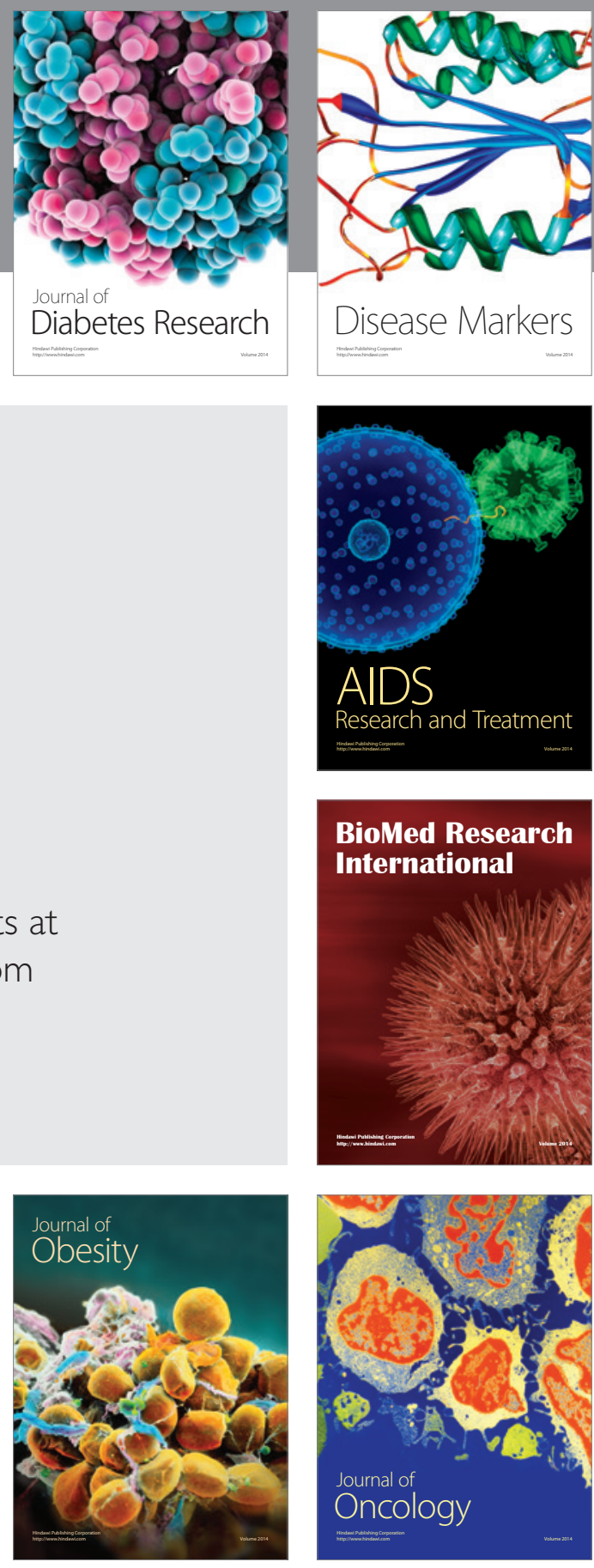

Disease Markers

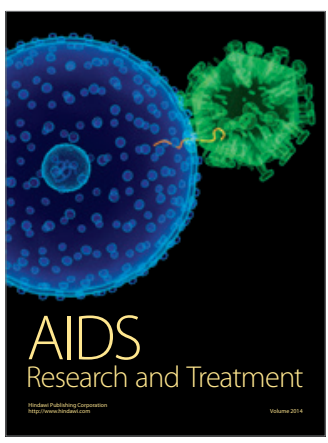

BioMed Research

International
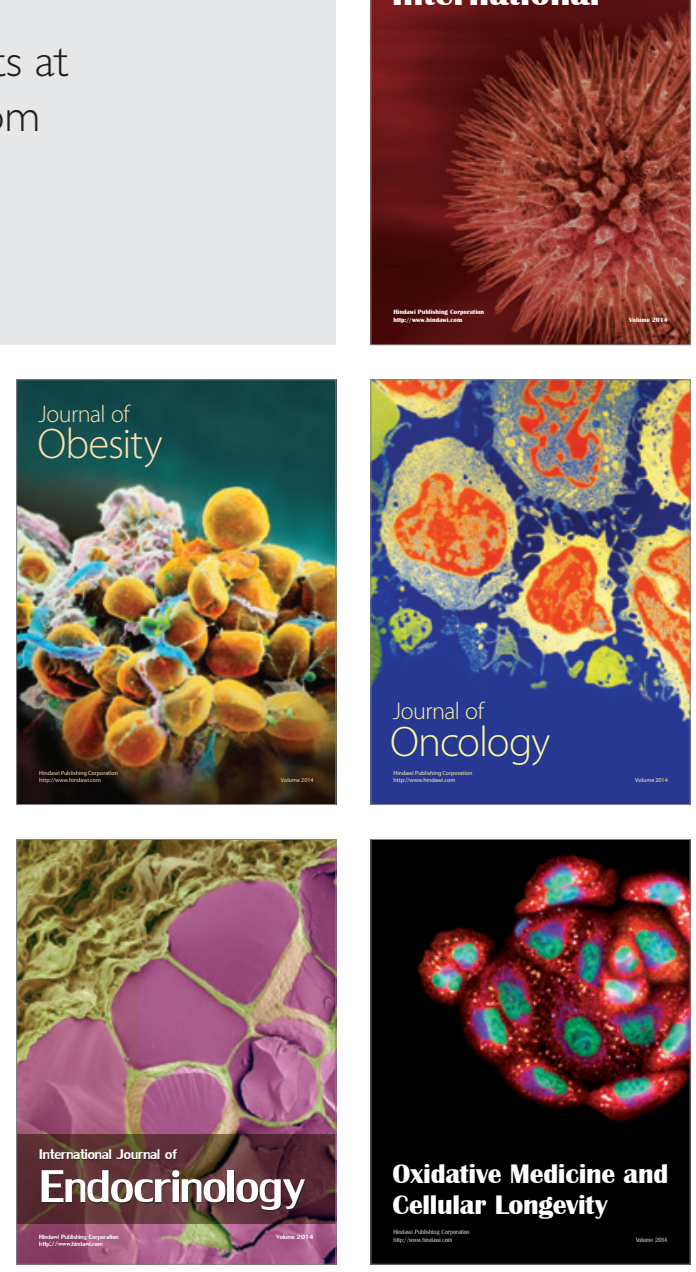